\title{
Leptin neutralization interferes with pathogenic T cell autoreactivity in autoimmune encephalomyelitis
}

\author{
Veronica De Rosa, ${ }^{1,2}$ Claudio Procaccini, ${ }^{1,2}$ Antonio La Cava, ${ }^{3}$ Paolo Chieffi, ${ }^{4}$ \\ Giovanni Francesco Nicoletti, ${ }^{5}$ Silvia Fontana, ${ }^{1}$ Serafino Zappacosta, ${ }^{2}$ and Giuseppe Matarese ${ }^{1,2}$ \\ ${ }^{1}$ Istituto di Endocrinologia e Oncologia Sperimentale, Consiglio Nazionale delle Ricerche (IEOS-CNR), Naples, Italy. \\ ${ }^{2}$ Cattedra di Immunologia, Dipartimento di Biologia e Patologia Cellulare e Molecolare, Università di Napoli "Federico II", Naples, Italy. \\ ${ }^{3}$ Autoimmunity and Tolerance Laboratory, Department of Medicine, University of California Los Angeles, Los Angeles, California, USA. \\ ${ }^{4}$ Dipartimento di Medicina Sperimentale and ${ }^{5}$ Dipartimento di Chirurgia Plastica, Seconda Università di Napoli, Naples, Italy.
}

\begin{abstract}
Recent evidence has indicated that leptin, an adipocyte-secreted hormone belonging to the helical cytokine family, significantly influences immune and autoimmune responses. We investigate here the mechanisms by which in vivo abrogation of leptin effects protects $\mathrm{SJL} / \mathrm{J}$ mice from proteolipid protein peptide $\mathrm{PLP}_{139-151^{-}}$ induced EAE, an animal model of MS. Blockade of leptin with anti-leptin Abs or with a soluble mouse leptin receptor chimera (ObR:Fc), either before or after onset of EAE, improved clinical score, slowed disease progression, reduced disease relapses, inhibited $\mathrm{PLP}_{139-151}$-specific $\mathrm{T}$ cell proliferation, and switched cytokine secretion toward a Th2/regulatory profile. This was also confirmed by induction of forkhead box p3 (Foxp3) expression in $\mathrm{CD}^{+} \mathrm{T}$ cells in leptin-neutralized mice. Importantly, anti-leptin treatment induced a failure to downmodulate the cyclin-dependent kinase inhibitor $\mathrm{p} 27\left(\mathrm{p}^{27^{\mathrm{Kip}}-1}\right)$ in autoreactive CD4 ${ }^{+} \mathrm{T}$ cells. These effects were associated with increased tyrosine phosphorylation of both ERK1/2 and STAT6. Taken together, our data provide what we believe is a new molecular basis for leptin antagonism in EAE and envision novel strategies of leptin-based molecular targeting in the disease.
\end{abstract}

\section{Introduction}

Leptin is a cytokine-like hormone that links nutritional status with the immune system $(1,2)$. It is mainly produced by adipose tissue in proportion to body mass index and at lower levels by organs such as the stomach and placenta $(1,2)$. Leptin regulates body weight through inhibition of food intake and stimulation of energy expenditure. Moreover, leptin affects both innate and adaptive immunity $(2,3)$. On innate immunity, leptin modulates the activity of neutrophils, increases the phagocytosis of monocytes/macrophages, and enhances the secretion of inflammatory mediators of the acute phase response $(2,3)$. On adaptive immunity, leptin promotes proliferation and IL-2 secretion by naive T cells, whereas on memory $\mathrm{T}$ cells it promotes the switch toward Th1 immune response by increasing IFN- $\gamma$ and TNF- $\alpha$ secretion $(2,3)$. Another important role of leptin in adaptive immunity is highlighted by the observation that leptin-deficient $o b / o b$ mice are resistant to induction of EAE, an animal model of MS $(2,4)$.

EAE can be induced in susceptible strains of mice by immunization with self antigens derived from myelin. The disease is characterized by chronic or relapsing/remitting paralysis due to autoreactive Th $1 \mathrm{CD}^{+}$cells that infiltrate the brain and spinal cord and damage the self antigen myelin $(5,6)$. A direct role of $\mathrm{CD}^{+} \mathrm{T}$ cells in the pathogenesis of EAE has been demonstrated in adoptive transfer studies, where myelin-reactive $\mathrm{Th} 1 \mathrm{CD} 4^{+} \mathrm{T}$ cells induced the disease after transfer $(5,6)$.

Nonstandard abbreviations used: DTH, delayed-type hypersensitivity; Foxp3, fork-

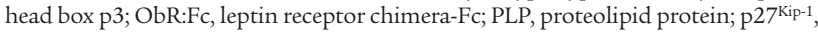
cyclin-dependent kinase inhibitor p27; VLA-4, very late antigen-4.

Conflict of interest: The authors have declared that no conflict of interest exists. Citation for this article: J. Clin. Invest. 116:447-455 (2006). doi:10.1172/JCI26523.
We have recently reported that leptin administration to susceptible mice worsens EAE by increasing secretion of proinflammatory cytokines (4). In a similar fashion, leptin replacement in leptin-deficient $o b / o b$ mice restores susceptibility to both active and passive EAE (4). Since we and others have also described that leptin is expressed in active inflammatory lesions of the CNS during acute EAE and MS (7-9), we investigated the molecular effects of leptin neutralization either with anti-mouse leptin Abs or with soluble mouse leptin receptor chimera-Fc (ObR:Fc), on induction and progression of EAE.

\section{Results}

Leptin blockade improves clinical score and delays disease progression in actively induced EAE. We evaluated the ability of either anti-leptin neutralizing Abs or ObR:Fc to affect induction and progression of EAE after immunization with proteolipid protein 139-151 (PLP $\left.{ }_{139-151}\right)$ myelin peptide. Treatment with anti-leptin Abs or ObR:Fc was initiated prior to immunization (from day -1 to day 1 relative to immunization) or during the acute phase of the disease (days 8-11), for 3 and 4 consecutive days, respectively (Figure 1, $A$ and B, and Table 1; see Methods for details). In both cases, leptin neutralization led to a statistically significant reduction in EAE clinical score and percentage of initial body weight loss as well as a reduced number of inflammatory infiltrates (Figure 1, A and B, and Table 1). These effects led to significant clinical improvement and delayed disease progression during the following 40 days of observation (Figure 1, A and B, and Table 1), indicating that leptin blockade inhibited both development and progression of EAE. Moreover, observation of animals over a longer period of time (90-120 days) revealed a significant reduction in relapse rate (Table 1), suggesting that this protection was long lasting. 

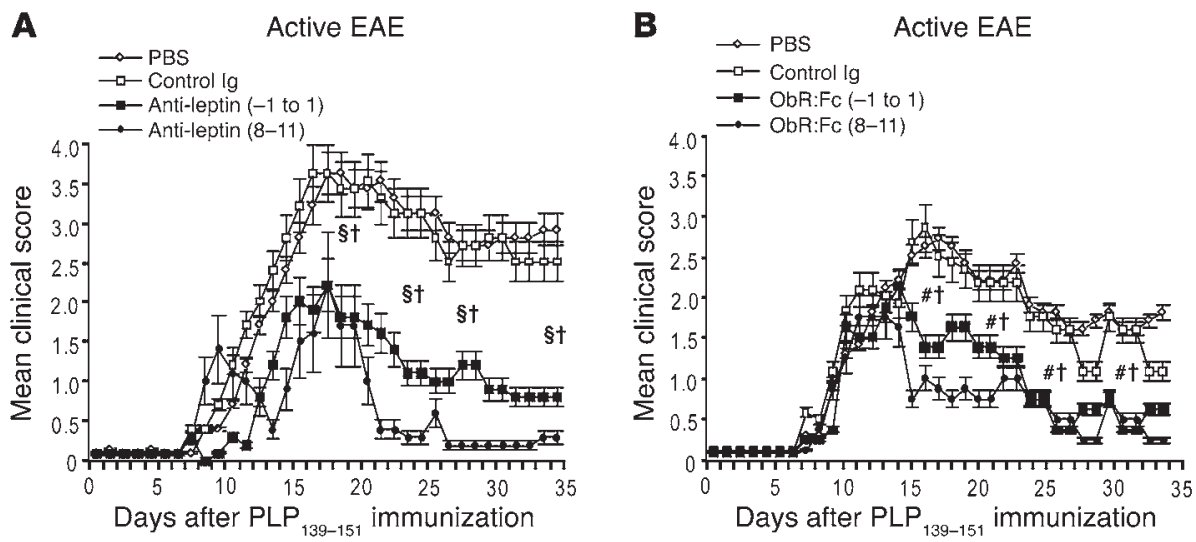

Figure 1

Leptin blockade during actively induced EAE with either anti-leptin Abs or ObR:Fc reduces the clinical severity of EAE. (A) Mean clinical score of SJL/J female mice treated with anti-mouse leptin Abs injected either from day -1 to day 1 or on days $8-11$ (100 $\mu \mathrm{g} / \mathrm{d}$ i.p.). Leptin blockade significantly delayed disease onset and reduced clinical score and body weight loss (see Table 1). Data are from 1 representative experiment of 3. (B) Mean clinical score of SJL/J female mice treated with mouse ObR:Fc chimera injected either from day -1 to day 1 or on days $8-11$ (100 $\mu \mathrm{g} / \mathrm{d}$ i.p.). Data are from 1 representative experiment of $3 .{ }^{\S} P=0.01$, day -1 to day $1,{ }^{\sharp} P=0.02$, day -1 to day 1 , and ${ }^{\dagger} P=0.04$, days 8-11, versus PBS or control lg.

Leptin blockade improves clinical score and delays disease progression in passively induced EAE. We next tested the ability of either anti-leptin Abs or ObR:Fc to modify the onset and progression of adoptively transferred EAE (Figure 2, A and B, and Table 1). Treatment with Abs was repeated for 3-4 consecutive days, before (from day -1 to day 1 ) or after (days $8-11$ ) the adoptive transfer of $2 \times 10^{7}$ puri-

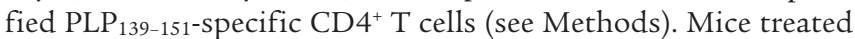

with control Igs all developed severe EAE (Figure 2A and Table 1). In contrast, mice treated with anti-leptin Abs from day - 1 to day 1 displayed a milder disease (Figure 2A and Table 1), while those treated on days 8-11 were fully protected (Figure 2A and Table 1). Treatment with ObR:Fc from day -1 to day 1 also led to a reduction of EAE clinical signs and delayed progression of the disease with significantly more efficiency than did anti-leptin Ab treatment from day -1 to day 1 (Figure 2, $\mathrm{A}$ and $\mathrm{B}$, and Table 1). A significant reduction in the relapse rate was also found in animals observed for 90-120 days (Table 1).

Leptin blockade is accompanied by inbibition of delayed-type bypersensitivity and reduces autoreactive $T$ cell proliferation to PLP ${ }_{139-151}$ peptide during EAE. To determine the nature of the in vivo $T$ cell response against $\mathrm{PLP}_{139-151}$ peptide in leptin-neutralized mice, delayed-type hypersensitivity (DTH) reactions were performed in all groups of mice. On day 35 of observation, mice were challenged with $25 \mu \mathrm{g} \mathrm{PLP}_{139-151}$ peptide injected intradermally in the footpad. The degree of local footpad swelling was measured as readout for the DTH reaction (see Methods). Typical DTH kinetics were observed with footpad swelling peaking between 24-48 hours and subsiding after 72-96 hours. DTH responses to the $\mathrm{PLP}_{139-151}$ peptide priming epitope were

\section{Table 1}

Effect of treatment with either anti-leptin Abs or ObR:Fc chimera on neurological impairment during active and passive EAE in SJL/J female mice

\begin{tabular}{|c|c|c|c|c|c|c|c|}
\hline Group & $\begin{array}{c}\text { Incidence, } \\
\text { no./total (\%) }\end{array}$ & $\begin{array}{l}\text { Day of onset } \\
\text { (range) }\end{array}$ & $\begin{array}{l}\text { Peak clinical } \\
\text { score }\end{array}$ & $\begin{array}{l}\text { Average } \\
\text { CDIA }\end{array}$ & $\begin{array}{l}\text { Body wt at disease } \\
\text { peak (\% of original) }\end{array}$ & $\begin{array}{l}\text { No. inflammatory } \\
\text { foci }\end{array}$ & $\begin{array}{l}\text { Relapse rate } \\
\text { after treatment }\end{array}$ \\
\hline PBS (active EAE) & $18 / 18(100.0)$ & $9.0 \pm 0.5(8-9)$ & $3.6 \pm 0.9$ & $70.9 \pm 13.0$ & $71.5 \pm 0.8$ & $45.5 \pm 10.0$ & 2.00 \\
\hline Control IgM & $18 / 18(100.0)$ & $8.1 \pm 0.5(8-9)$ & $3.5 \pm 1.0$ & $70.3 \pm 8.5$ & $74.7 \pm 0.5$ & $40.1 \pm 5.0$ & 1.94 \\
\hline Anti-leptin (-1 to 1$)$ & $18 / 18(100.0)$ & $11.8 \pm 1.0(10-13)$ & $2.0 \pm 0.5^{c}$ & $30.7 \pm 6.0^{c}$ & $83.8 \pm 0.6^{c}$ & $15.5 \pm 10.0^{C}$ & 0.55 \\
\hline Anti-leptin $(8-11)$ & $18 / 18(100.0)$ & $12.1 \pm 3.0(8-16)$ & $1.6 \pm 0.8^{D}$ & $20.1 \pm 10.7^{D}$ & $95.1 \pm 0.6 \mathrm{D}$ & $9.0 \pm 4.0^{\mathrm{D}}$ & 0.33 \\
\hline PBS (active EAE) & $18 / 18(100.0)$ & $8.0 \pm 0.5(8-9)$ & $2.7 \pm 0.8$ & $51.7 \pm 8.0$ & $77.0 \pm 0.5$ & $31.0 \pm 10.0$ & 1.55 \\
\hline Control IgG1 & $18 / 18(100.0)$ & $8.1 \pm 0.4(8-9)$ & $2.6 \pm 0.5$ & $49.5 \pm 7.0$ & $77.5 \pm 0.5$ & $31.9 \pm 12.0$ & 1.66 \\
\hline ObR:Fc (-1 to 1$)$ & $18 / 18(100.0)$ & $9.4 \pm 1.0(8-12)$ & $1.2 \pm 0.4^{C}$ & $28.5 \pm 10.0^{C}$ & $87.5 \pm 0.4 c$ & $15.0 \pm 7.0^{C}$ & 0.55 \\
\hline ObR:Fc (8-11) & $17 / 18(94.4)$ & $9.0 \pm 0.5(8-10)$ & $0.9 \pm 0.5^{\mathrm{D}}$ & $22.1 \pm 12.0^{\mathrm{D}}$ & $101.4 \pm 0.1^{D}$ & $11.0 \pm 5.0^{\mathrm{D}}$ & 0.55 \\
\hline PBS (passive EAE) & 18/18 (100.0) & $7.1 \pm 1.0(6-8)$ & $2.8 \pm 1.0$ & $39.0 \pm 5.0$ & $75.1 \pm 1.0$ & $27.0 \pm 5.0$ & 1.38 \\
\hline Control IgM & $18 / 18(100.0)$ & $7.0 \pm 0.7(6-8)$ & $2.6 \pm 0.8$ & $36.6 \pm 3.0$ & $79.0 \pm 0.8$ & $27.5 \pm 6.0$ & 1.44 \\
\hline Anti-leptin (-1 to 1$)$ & $18 / 18(100.0)$ & $8.8 \pm 2.0(6-11)$ & $1.6 \pm 0.8^{C}$ & $25.9 \pm 6.0^{C}$ & $81.5 \pm 1.2^{\mathrm{C}}$ & $10.5 \pm 9.0^{C}$ & 0.61 \\
\hline Anti-leptin (8-11) & $14 / 18(77.7)$ & $17.8 \pm 1.1(17-20)$ & $0.3 \pm 0.4^{D}$ & $6.6 \pm 2.0^{\mathrm{D}}$ & $106.0 \pm 2.0^{D}$ & $0.2 \pm 0.5^{\mathrm{D}}$ & 0.05 \\
\hline PBS (passive EAE) & 18/18 (100.0) & $7.2 \pm 1.2(7-8)$ & $3.1 \pm 1.0$ & $44.5 \pm 3.0$ & $78.0 \pm 1.0$ & $35.5 \pm 6.0$ & 1.27 \\
\hline Control IgG1 & $18 / 18(100.0)$ & $7.5 \pm 0.7(7-8)$ & $3.0 \pm 0.9$ & $41.5 \pm 2.5$ & $78.0 \pm 2.0$ & $34.3 \pm 10.5$ & 1.33 \\
\hline ObR:Fc (-1 to 1$)$ & $14 / 18(77.7)$ & $9.5 \pm 0.7(8-10)$ & $0.5 \pm 0.0^{\mathrm{D}}$ & $8.6 \pm 1.0^{\mathrm{D}}$ & $101.4 \pm 1.2^{\mathrm{D}}$ & $0.5 \pm 0.1^{D}$ & 0.00 \\
\hline ObR:Fc (8-11) & $13 / 18(72.2)$ & $10.0 \pm 0.7(8-10)$ & $0.5 \pm 0.0^{\mathrm{D}}$ & $10.5 \pm 1.0^{\mathrm{D}}$ & $102.9 \pm 2.0^{D}$ & $0.5 \pm 0.4^{\mathrm{D}}$ & 0.00 \\
\hline
\end{tabular}

Data were cumulated and averaged from 3 independent experiments, each performed with 6 mice per group, and are presented as mean \pm SD. See Methods for details of isotype controls utilized. CDI, cumulative disease index. AThe sum of daily scores was determined for each mouse of the indicated group and averaged. ${ }^{B}$ Calculated as total number of relapses per group divided by the total number of mice in that group (mice were observed up to $90-120$ days after disease induction to asses the relapse rate). ${ }^{C} P=0.001$ and $D P=0.0001$ versus respective PBS and control lg groups. 

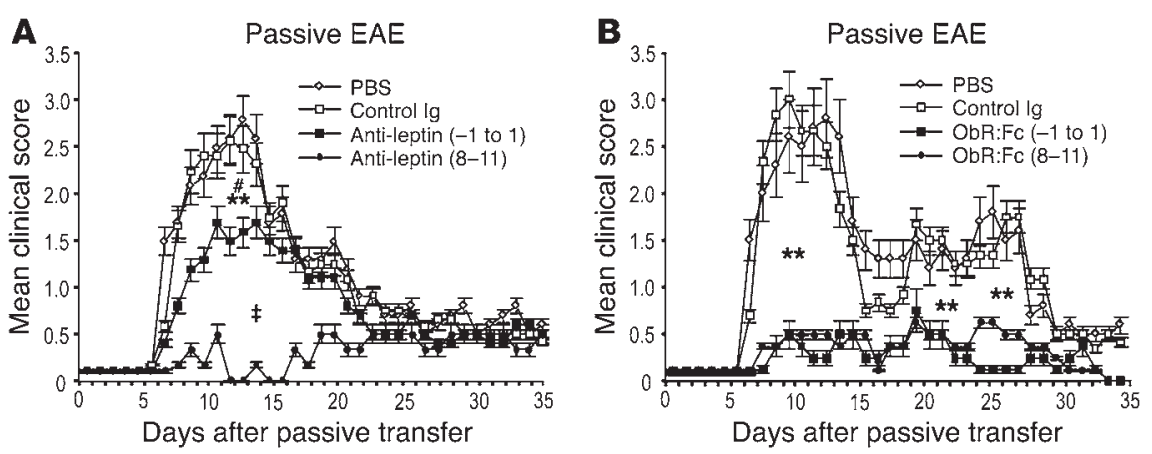

Figure 2

Leptin blockade during adoptively transferred EAE with either anti-leptin Abs or ObR:Fc chimera reduces the clinical severity of EAE. (A) Mean clinical score of SJL/J female mice treated with anti-mouse leptin Abs injected either from day -1 to day 1 or on days $8-11$ (100 $\mu \mathrm{g} / \mathrm{d}$ i.p.). Leptin blockade significantly reduced clinical score and body weight loss (see Table 1). Data are from 1 representative experiment of 3 . ${ }^{\#} P=0.02$, day -1 to day 1 , and ${ }^{* *} P=0.001$, days $8-11$, versus PBS or control Ig; $¥ P=0.02$, day -1 to day 1 versus days $8-11$. (B) Mean clinical score of SJL/J female mice treated with mouse ObR:Fc chimera injected either from day -1 to day 1 or on days $8-11$ (100 $\mu \mathrm{g} / \mathrm{d}$ i.p.). Data are from 1 representative experiment of $3 .{ }^{* \star} P=0.001$, day -1 to day 1 and days $8-11$ versus control lg.

significantly reduced in mice treated with anti-leptin Abs and ObR:Fc, whereas the controls exhibited a marked DTH reaction (Figure $3 \mathrm{~A}$ and Figure 4A).

We also examined whether leptin blockade could affect proliferation of $\mathrm{PLP}_{139-151}$-specific $\mathrm{T}$ cells in vitro. $\mathrm{T}$ cell response to $\mathrm{PLP}_{139-151}$ peptide was tested on draining lymph nodes taken from all groups of treated mice 15 days after immunization and cul-

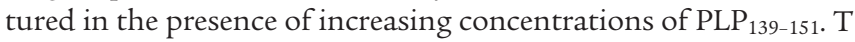
cells derived from either anti-leptin Abs- or ObR:Fc-treated mice showed a significant reduction in proliferation (Figure 3B and Figure $4 \mathrm{~B}$, respectively), whereas no difference was observed when $\mathrm{T}$ cells were stimulated in parallel with a polyclonal stimulator such as the anti-CD3 $\mathrm{mAb}$ (2C11 hybridoma, Figure 3C and Figure 4C, respectively; see Methods). Of note, inhibition of in vitro anti-PLP $139-151$ proliferation was more efficient in mice treated with the ObR:Fc chimera (Figure 3B and Figure 4B).

Leptin blockade in EAE is associated with a switch of the cytokine profile toward a Th2/regulatory phenotype and upregulation of forkhead box $p 3$ expression. We next asked whether EAE protection was associated with an immune response characterized by considerable cytokine switching. The production of IFN- $\gamma$ was significantly reduced by both leptin-neutralizing treatments in the presence of increasing concentrations of $\mathrm{PLP}_{139-151}$ as well as during polyclonal anti-CD3 $\varepsilon$ stimulation (Figure 5, A and B, and Figure 6, A and B). In addition, a significant increase in the Th2/regulatorytype cytokines such as IL-4 (Figure 5, C and D, and Figure 6, C and D) and IL-10 (Figure, 5, E and F, and Figure 6, E and F) was observed during both anti-PLP ${ }_{139-151^{-}}$ specific proliferation and polyclonal stimulation with anti-CD3 $\varepsilon$. In addition, to determine whether treatment with ObR:Fc induced forkhead box $\mathrm{p} 3$ (Foxp3) expression in CD4 ${ }^{+}$ $T$ cells, we isolated these cells from mice with EAE and measured Foxp3 expression by Western blot. Leptin neutralization induced significant increase of Foxp3 levels (Figure 7, A and B), suggesting induction of regulatory $\mathrm{T}$ cell markers in leptin-neutralized mice.

Leptin neutralization reduces the expression of ICAM-1 and OX-40 and upregulates very late antigen-4 on $\mathrm{CD}^{+} \mathrm{T}$ cells during EAE. We then investigated in more detail the cellular events leading to an improvement of clinical symptoms and progression of EAE. Cytofluorimetric analysis of $\mathrm{CD} 4^{+} \mathrm{T}$ cells from mice treated with anti-leptin Abs or ObR:Fc obtained on day 15 after immunization with PLP $_{139-151}$ revealed a significant reduction of ICAM-1 and
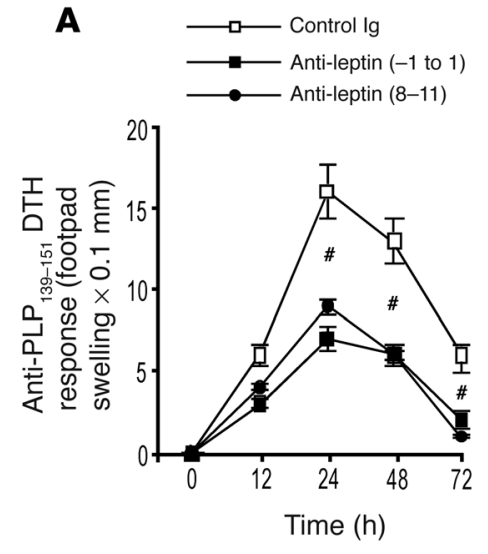

Figure 3

In vivo leptin neutralization with anti-mouse leptin Abs in SJL/J mice inhibits DTH response and induces T cell hyporesponsiveness to PLP $139-151$ myelin peptide. (A) DTH reaction in leptin-neutralized and control Ig-treated mice measured as footpad swelling. Data are from 1 representative experiment of 2. (B) Proliferative response of lymph node-derived T cells against PLP ${ }_{139-151}$ was impaired after treatment with anti-mouse leptinneutralizing Abs compared with the control Ig-treated group. Data are from 1 representative experiment of 3. (C) Anti-mouse leptin treatment did not affect polyclonal T cell proliferation induced with anti-CD3 $\varepsilon$ stimulation. ${ }^{2} P=0.02$, day -1 to day 1 and days $8-11$ versus control lg.

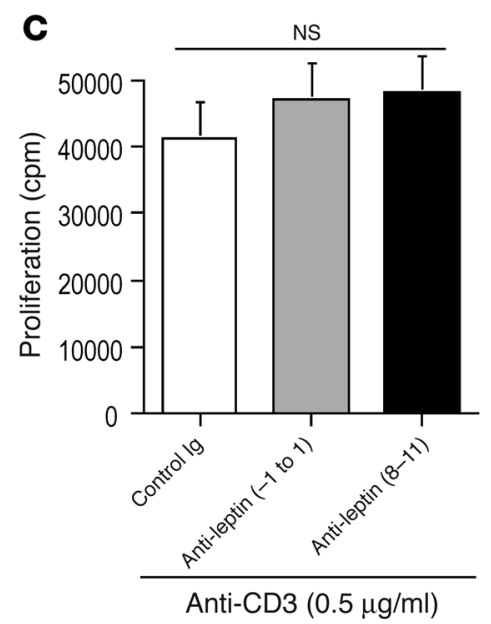




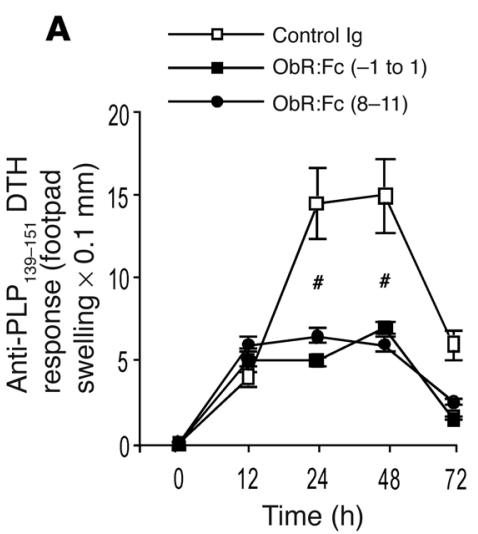

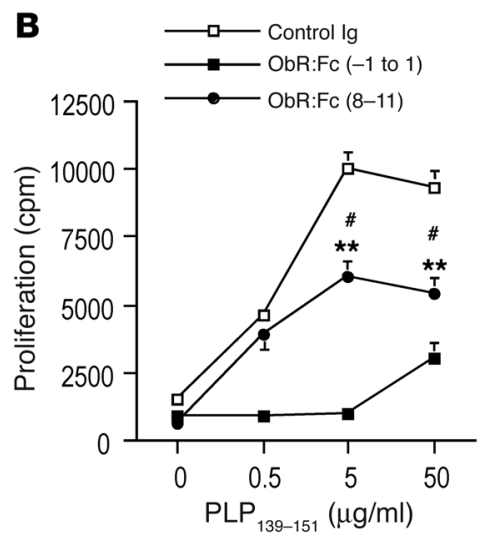

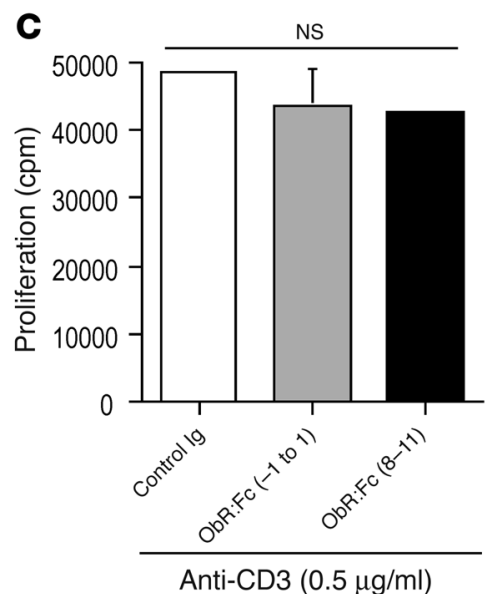

\section{Figure 4}

In vivo leptin neutralization with mouse ObR:Fc chimera in SJL/J mice inhibits DTH response and induces T cell hyporesponsiveness to PLP ${ }_{139-151}$ myelin peptide. (A) DTH reaction in ObR:Fc leptin-neutralized and control Ig-treated mice measured as footpad swelling. Data are from 1 representative experiment of 2 . ${ }^{\#} P=0.02$, day -1 to day 1 and days $8-11$ versus control Ig. (B) Proliferative response of lymph node-derived T cells against PLP ${ }_{139-151}$ was impaired after treatment with mouse ObR:Fc chimera compared with the control Ig-treated group. Data are from 1 representative experiment of $3 .{ }^{* \star} P=0.001$, day -1 to day 1 , and ${ }^{\#} P=0.02$, days $8-11$, versus control Ig. (C) ObR:Fc treatment did not affect

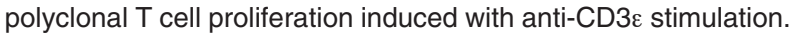

OX-40 (Figure 8, A and B, respectively), both classically involved in the pathogenesis of EAE (10-12). Conversely, the overall expression of the $\alpha 4 \beta 1$ integrin, very late antigen-4 (VLA-4) (13), was increased, with particular upregulation of the population at high fluorescence intensity (Figure 8C). The effects of leptin blockade on lymphocytes could not be ascribed to intrinsic toxicity of the molecule, as the circulating number and apoptosis (measured by annexin $\mathrm{V}$ staining) of $\mathrm{CD}^{+}, \mathrm{CD}^{+}, \mathrm{B}, \gamma \delta, \mathrm{NK}$, and monocytes in the spleen and lymph nodes of treated mice were not different from controls (data not shown).

Ex vivo $\mathrm{CD}^{+}$T cells from leptin-neutralized mice fail to downregulate the anergy factor cyclin-dependent kinase inhibitor $p 27$ and induce the ERK1/2 and STAT6 pathways. To evaluate whether leptin neutralization affects the molecular machinery of autoreactive $\mathrm{CD} 4^{+} \mathrm{T}$ cells, we analyzed a series of biochemical markers specific to $\mathrm{T}$ cell activation, anergy, and Th2/regulatory-type cytokine secretion (14-18). More specifically, we studied ex vivo purified $\mathrm{CD}^{+}$autoreactive $\mathrm{T}$ cells from spleens and lymph nodes of ObR:Fc-treated mice on day 15 of disease, previously immunized with PLP $_{139-151}$ peptide (see Methods). In CD4 ${ }^{+} \mathrm{T}$ cells ObR:Fc treatment led to a failure to downmodulate the cyclin-dependent kinase inhibitor p27 (p27 Kip-1; Figure 9A) associated with increased tyrosine phosphorylation of ERK1/2 (Figure 9B). Moreover, we observed an upregulation of STAT6 tyrosine phosphorylation levels (Y641, known to be associated with Th2/regulatory-type cytokine secretion; ref. 18) in ObR: Fc-treated mice compared with control mice (Figure 9C).

\section{Discussion}

Previous studies by our group and others have shown the relevance of leptin in the pathogenesis of EAE (4, 7-9). In particular, it was previously reported that $o b / o b$ mice are resistant to induction of the disease (4), whereas in wild-type, EAE-susceptible controls, a surge of serum leptin precedes acute EAE (7). In this work, we show for the first time to our knowledge that in vivo neutralization of leptin is effective at blocking initiation, progression, and clinical relapses of EAE, an animal model of MS (Figures 1 and 2 and Table 1).
We and others have previously reported that in the CNS of EAE mice, both infiltrating $T$ cells and neurons express leptin during the acute phase of the disease, and the degree of leptin expression within the lesions correlates with CNS inflammatory score and disease severity $(7,9)$. Because of the possibility of an autocrine loop sustaining autoreactive Th1 lymphocytes in EAE $(7,8)$, we investigated the DTH response as well as T cell proliferation and cytokine secretion in response to $\mathrm{PLP}_{139-151}$ in treated mice versus controls. Anti-leptin-treated animals showed reduced DTH and T cell proliferative responses to PLP $_{139-151}$ peptide associated with a Th2/regulatory-type cytokine shift (Figures 3-6). This evidence was also supported by increased expression levels of the regulatory $\mathrm{T}$ cell master gene Foxp 3 in $\mathrm{CD}^{+} \mathrm{T}$ cells from mice with EAE (Figure 7).

It is interesting to note that in vivo leptin neutralization differentially affected proliferative responses and regulatory cytokine switch during polyclonal anti-CD3 stimulation (Figures 3-6). Indeed, while we observed a reduction of proliferation and a Th2/regulatory cytokine switch toward $\mathrm{PLP}_{139-151}$, anti-CD3 polyclonal stimulation was only affected in terms of cytokine secretion and not of proliferative response at the relatively low doses of leptin blockers utilized in vivo. The evidence that leptin itself differentially influences polyclonal versus antigen-specific proliferation and cytokine secretion may account for these apparently contrasting effects (19). On the other hand, it is also possible to speculate that leptin neutralization-induced perturbations of the cytokine milieu during antigen-specific stimulation may preferentially modulate cytokine profile rather than proliferative responses induced by anti-CD3.

Leptin blockade also affected expression of ICAM-1, OX-40, and VLA-4 on CD4 ${ }^{+} \mathrm{T}$ cells (Figure 8 ). In particular, reduced expression of ICAM-1 was consistent with our previous findings showing that leptin treatment increases surface expression of this adhesion molecule on T cells (20). This finding suggested the possibility that neutralization of leptin directly affects the cognate interaction leading to reactive and/or autoreactive $\mathrm{T}$ cell activation. More- 
A
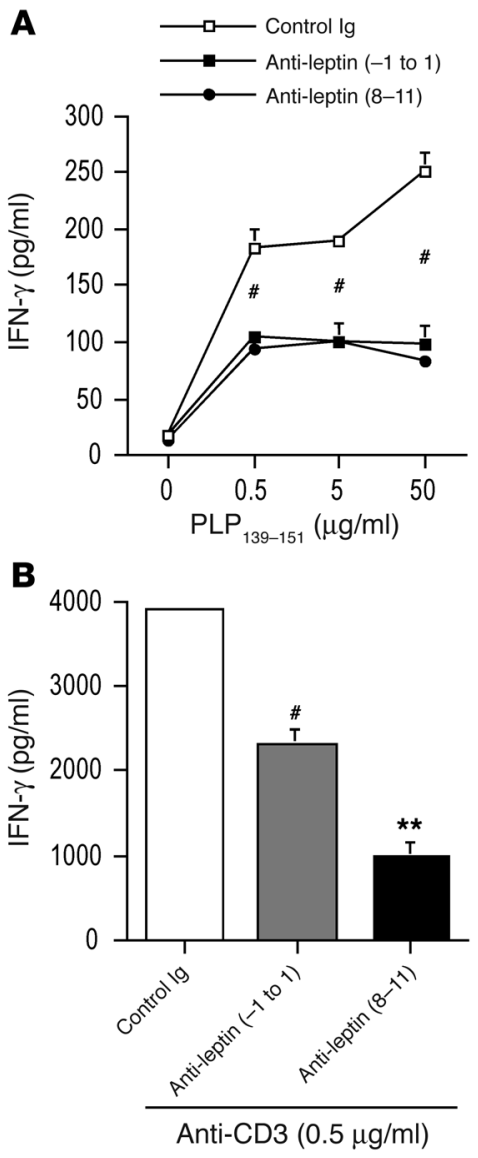
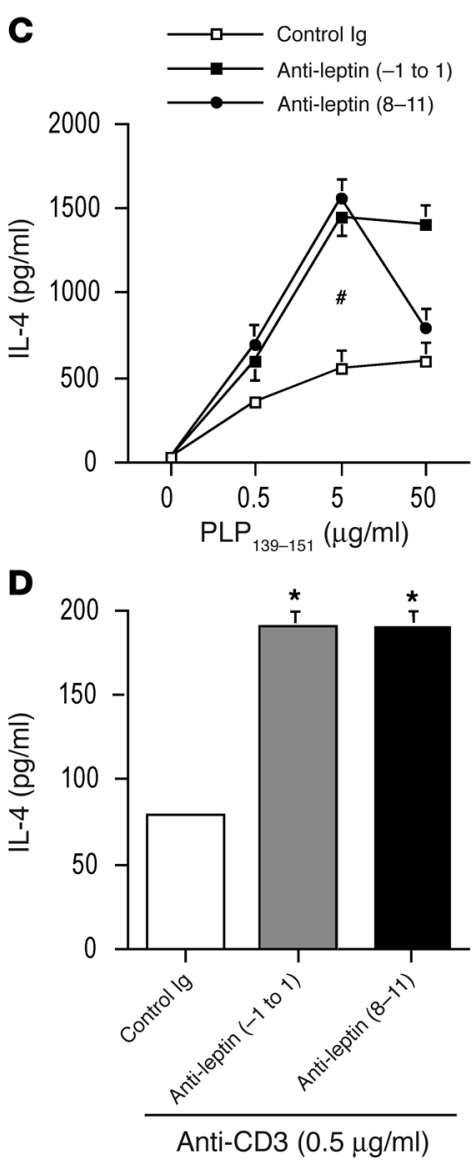

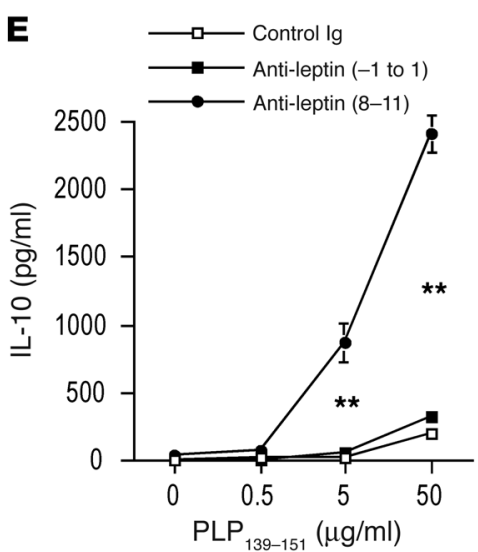

$\mathbf{F}$

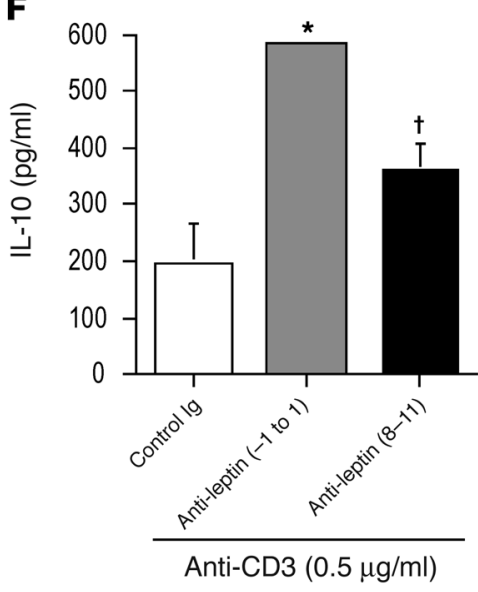

Figure 5

In vivo leptin neutralization with anti-mouse leptin Abs inhibits IFN- $\gamma$ production and induces the secretion of IL-4 and IL-10 regulatory cytokines. (A and B) IFN- $\gamma$ secretion of lymph node-derived T cells was inhibited by anti-leptin treatment when T cells were stimulated with the myelin anti-

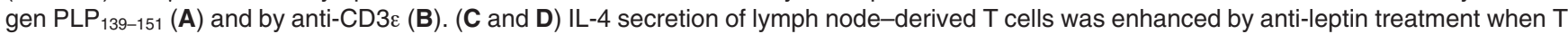

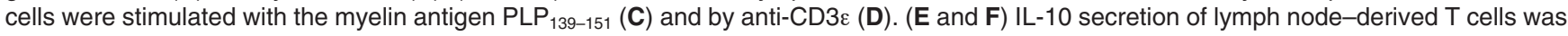

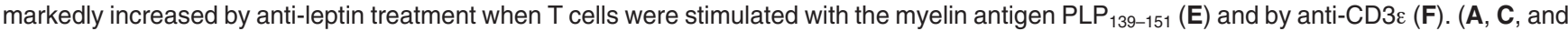
E) ${ }^{\#} P=0.02$, day -1 to day 1 and days $8-11$, and ${ }^{\star \star} P=0.001$, days $8-11$, versus control Ig. Data are from 1 representative experiment of 3 . (B, D, and F) ${ }^{\#} P=0.02,{ }^{* *} P=0.001,{ }^{*} P=0.002,{ }^{\dagger} P=0.04$ versus control lg.

over, marked reduction of OX-40 was also observed after leptin blockade. Since OX-40 is an important costimulatory molecule with prosurvival activity for $\mathrm{CD}^{+} \mathrm{T}$ cells, and signaling through this molecule breaks peripheral $\mathrm{T}$ cell tolerance $(11,21)$, our data suggest that leptin may affect expression of key molecules on $T$ lymphocytes involved in the mechanisms of immune tolerance. Surprisingly, we also observed that leptin neutralization induced increased expression of VLA-4, the $\alpha 4 \beta 1$ integrin shown to play an integral part in the homing and migration of cells that induce EAE (13). However, experimental evidence has shown that administration of anti-VLA-4 ameliorated EAE only if it was initiated before disease onset, whereas treatment during acute disease exacerbated EAE and enhanced the accumulation of T cells in the CNS (13). Therefore, we are tempted to hypothesize that the induction of VLA-4 on CD4 $4^{+} \mathrm{T}$ cells after leptin neutralization could be associated in part with an increased cell capability to migrate into the CNS and produce regulatory cytokines able to downmodulate EAE. Of note, these data are in agreement with other findings showing that adhesion molecules are increased on regulatory $\mathrm{T}$ cells in experiments of protection from $\operatorname{EAE}(22,23)$.
To further address, at the biochemical level, whether in vivo leptin neutralization interferes with the signalling capacity of autoreactive $T$ cells, we analyzed several molecular pathways associated with $\mathrm{T}$ cell anergy/activation and cytokine switch (14-18). We found that $\mathrm{CD}^{+} \mathrm{T}$ cells from mice treated with leptin antagonists showed hyporesponsiveness to $\mathrm{PLP}_{139-151}$ peptide, which was indicated by accumulation of $\mathrm{p} 27^{\mathrm{Kip}-1}$. This negative cell cycle regulator plays a central role in blocking clonal expansion of $\mathrm{T}$ cells and is therefore critical for anergy induced by blockade of costimulatory pathways $(14,17,24)$. We also found that the hyporesponsive state induced by leptin antagonism was associated with marked increase of ERK1/2 phosphorylation, confirming involvement of ERK1/2 in the improvement of EAE (25). It is interesting to observe that our findings with leptin antagonism seem to involve pathways affected by statins, cholesterol-lowering drugs that have recently been shown to reduce production of leptin by adipocytes (26), promote Th2 responses, and improve EAE (27) by disabling downregulation of p2 $7^{\text {Kip-1 }}$ and upregulating phosphorylation of ERK1/2 (28). Finally, we also observed at the biochemical level the induction of phosphorylation of the 

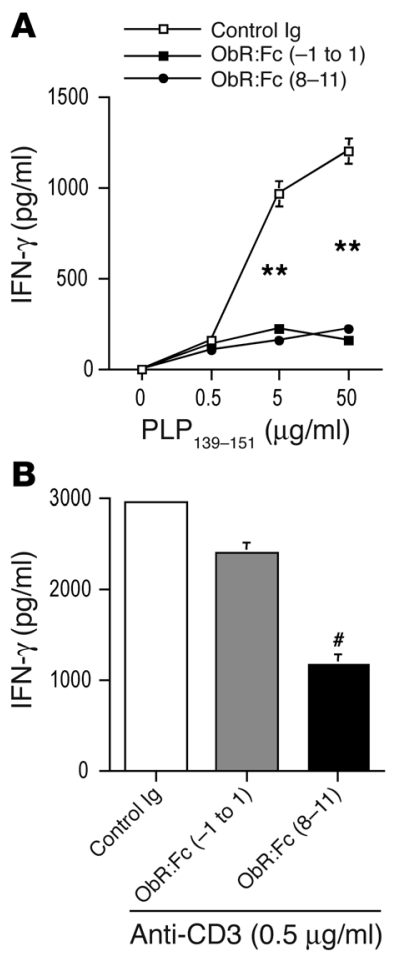

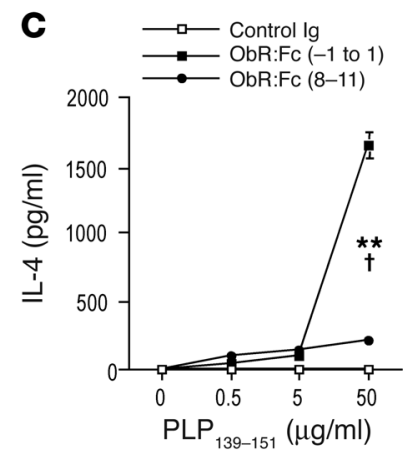

D

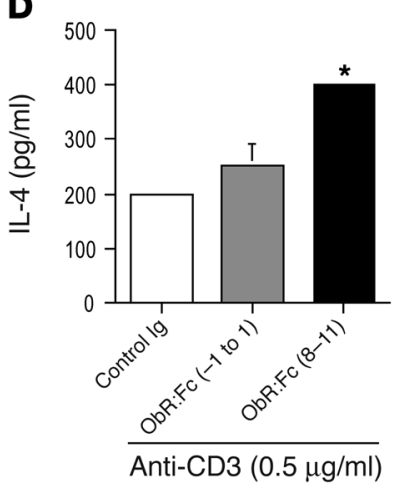

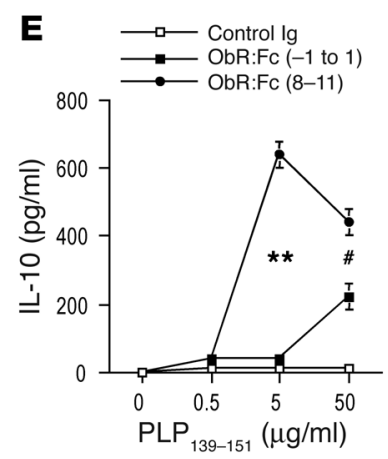

$\mathbf{F}$

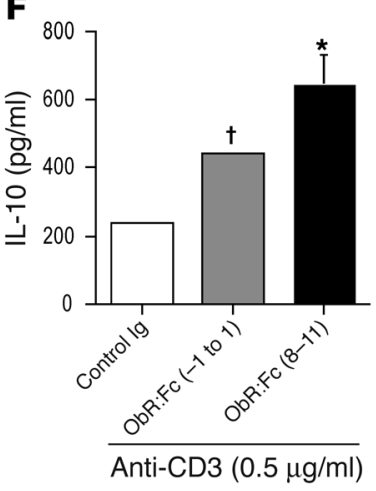

Figure 6

In vivo leptin neutralization with ObR:Fc inhibits IFN- $\gamma$ production and induces the secretion of IL-4 and $\mathrm{IL}-10$ regulatory cytokines. (A and $\mathbf{B}$ ) IFN- $\gamma$ secretion of lymph node-derived T cells was inhibited by ObR:

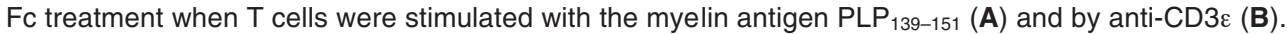
(C and D) IL-4 secretion of lymph node-derived T cells was enhanced by ObR:Fc treatment when T cells were stimulated with the myelin antigen PLP $_{139-151}$ (C) and by anti-CD3E (D). (E and F) IL-10 secretion of lymph node-derived T cells was markedly increased by ObR:Fc treatment when $T$ cells were stimulated with the myelin antigen $\operatorname{PLP}_{139-151}(\mathbf{E})$ and by anti-CD3 $\varepsilon(\mathbf{F})$. Data are from 1 representative experiment of 3. (A) ${ }^{* *} P=0.001$, day -1 to day 1 and days $8-11$ versus control Ig. (C) ${ }^{* *} P=0.001$, day -1 to day 1 , and ${ }^{\dagger} P=0.04$, days $8-11$, versus control Ig. $(\mathrm{E}){ }^{* *} P=0.001$, days $8-11$, and ${ }^{*} P=0.02$, day -1 to day 1 , versus control Ig. (B, D, and $\mathbf{F}){ }^{\#} P=0.02,{ }^{*} P=0.002,{ }^{\dagger} P=0.04$ versus control Ig.

STAT6 transcription factor, well known to be able to induce the transcription of IL-4 and associated with a classical Th2/regulatory-type cytokine response during EAE (18).

In conclusion, we report that leptin neutralization was able to improve clinical onset, progression, and clinical relapses of both actively induced and passively transferred EAE. This effect was associated with marked inhibition of DTH reaction against PLP $_{139-151}$ peptide, $\mathrm{CD}^{+} \mathrm{T}$ cell hyporesponsiveness, and increased IL-4 and IL-10 production against myelin antigens. Foxp3 expression was also induced on $\mathrm{CD}^{+} \mathrm{T}$ cells in leptin-neutralized mice, suggesting the induction of a regulatory phenotype. At the biochemical level, $\mathrm{T}$ cell hyporesponsiveness might be explained by the failure to downmodulate the anergy factor $\mathrm{p} 27^{\mathrm{Kip}-1}$ and by the increase in the tyrosine phosphorylation levels of ERK1/2 and STAT6. Taken together, our results provide a framework for leptin-based intervention in EAE and identify molecules with possible therapeutic potential for the disease.

\section{Methods}

Mice. Female SJL/J mice (H-2 $)$, 6-8 weeks old, were obtained from HarlanItaly. All animal experiments were approved by the Istituto Superiore di Sanità (Rome, Italy). All mice were age matched for individual experiments and were group housed (2-6 mice per standard cage according to the differcontrol (BD Biosciences - Pharmingen); for ObR:Fc fusion protein treatment, affinity-purified $\mathrm{IgG}_{1}$ was used as a control (BD Biosciences - Pharmingen).

EAE induction and clinical and histological assessment. For active induction of EAE, mice ( $n=6$ per group) were immunized s.c. in the flank with $100 \mu \mathrm{l}$ CFA (Difco; BD Diagnostics - Diagnostic Systems) emulsified with $100 \mu \mathrm{g}$ PLP $_{139-151}$ peptide on day 0 and with 200 ng pertussis toxin (Sigma-Aldrich s.r.l.) i.p. on days 0 and 1 . Control mice ( $n=5$ per group) were injected with CFA emulsified with PBS plus pertussis toxin according to the same schedule (data not shown). For adoptively transferred EAE, 9-10 female donor SJL/J mice (6-8 weeks old) were primed s.c. with $200 \mu \mathrm{g}$ PLP $_{139-151}$ peptide in CFA distributed over 4 sites. After 9-10 days, draining lymph nodes (axillary and inguinal) and spleens were harvested, homogenized into singlecell suspension, and cultured separately in vitro in 24 -well plates $\left(8 \times 10^{6}\right.$ cells/well, Falcon; BD) in the presence of $25 \mu \mathrm{g} / \mathrm{ml} \mathrm{PLP}_{139-151}$ peptide. After 4 days in culture, nonadherent cells were harvested and centrifuged over Ficoll gradient (Pharmacia), and $\mathrm{CD} 4^{+} \mathrm{T}$ cells were purified by passing the cells over the $\mathrm{CD}^{+}{ }^{+}$subset columns (R\&D Systems). Recipient syngeneic naive female SJL/J mice received, in a $200-\mu \mathrm{l}$ PBS i.v. injection, $2 \times 10^{7}$ highly purified $\mathrm{PLP}_{139-151}$-specific $\mathrm{CD}^{+} \mathrm{T}$ cells. Mice also received $200 \mathrm{ng}$ pertussis toxin immediately after cell transfer as well as 1 day later.

Individual mice were observed daily for clinical signs of disease for up to 40 days after immunization and after adoptive transfer. Mice were weighed and scored daily in a blinded fashion according to clinical severity of symptoms 
A

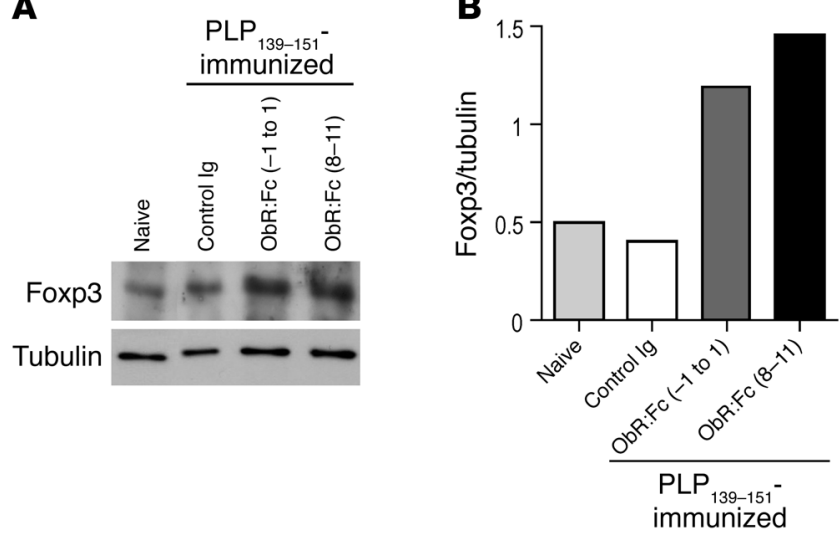

on a scale of 0 to 6 , with 0.5 points for intermediate clinical findings: grade 0 , no abnormality; grade 0.5 , partial loss of tail tonicity, assessed by inability to curl the distal end of the tail; grade 1, reduced tail tone or slightly clumsy gait; grade 2, tail atony, moderately clumsy gait, impaired righting ability, or any combination; grade 3 , hind limb weakness or partial paralysis; grade 4, complete hind limb paralysis or fore limb weakness; grade 5, tetraplegia or moribund state; grade 6 , death. The data were plotted as daily mean clinical score for all animals in a particular treatment group. Scores of asymptomatic mice (i.e., scores of 0 ) were included in the calculation of the daily mean clinical score for each group. A relapse was defined as a sustained (more than 2 days) increase in clinical score by at least 1 full grade after the animal had improved previously by at least 1 full grade and stabilized for at least 2 days. The data are plotted as the relapse rate of all the animals of that group (total number of relapses per group divided by total number of mice in the group; see Table 1). The brains and spinal cords were dissected between 15 and 20 days after immunization, according to the clinical stage of disease, and fixed in $10 \%$ formalin. Paraffinembedded sections of $5 \mu \mathrm{m}$ thickness were cut and stained with H\&E (Sigma-Aldrich). Sections from 4-10 segments per mouse were examined blindly for the number of inflammatory foci by using a previously published scoring system $(7,8)$.

In vivo Ab treatment. Mice were treated 3 or 4 times with $100 \mu \mathrm{g}$ control mouse IgM or control mouse $\operatorname{IgG}_{1}$ or with anti-mouse leptin-specific blockers (either anti-leptin Abs or ObR:Fc chimera, respectively) i.p. in a total volume of $100 \mu \mathrm{l}$ of PBS. Treatment was initiated with $\mathrm{PLP}_{139-151}$ peptide or the adoptive transfer of pathogenic $T$ cells for 3 consecutive days (days $-1,0$, and 1 ) or during the acute phase of the disease for 4 consecutive days (days 8-11).

Induction of DTH (footpad-swelling assay). DTH responses to $\mathrm{PLP}_{139-151}$ peptide during induction of disease were also quantitated using a time-dependent (12-72 hours) footpad-swelling assay. Briefly, mice previously sensitized with $\mathrm{PLP}_{139-151}$ in CFA

\section{Figure 8}

Leptin neutralization suppresses ICAM-1 and OX-40 expression on CD4+ cells but upregulates VLA-4 in mice with EAE. (A) Flow cytometric analysis of cell-surface ICAM-1 molecules on $\mathrm{CD}^{+} \mathrm{T}$ cells from ObR:Fc-treated mice and controls (left) and mean fluorescence intensity (MFI) from 3 independent experiments (right). (B) OX-40 surface expression was also reduced by ObR:Fc treatment. (C) VLA-4 expression was enhanced by $\mathrm{ObR}: \mathrm{Fc}$ treatment, particularly on $\mathrm{CD} 4+\mathrm{T}$ cells at high intensity. ${ }^{\#} P=0.02,{ }^{*} P=0.002,{ }^{\dagger} P=0.04$ versus control Ig.

\section{Figure 7}

Increased expression of Foxp3 in $\mathrm{CD}^{+} \mathrm{T}$ cells induced by leptin neutralization in mice with EAE. (A) Western blot analysis for Foxp3 on purified $\mathrm{CD}^{+}{ }^{+} \mathrm{T}$ cells obtained from SJL/J mice immunized with $\mathrm{PLP}_{139-151}$ revealed significant increase of the expression of this molecule after leptin neutralization with ObR:Fc. (B) Results are presented as Foxp3 protein level normalized to tubulin expression. Data are from 1 representative experiment of 3 .

were challenged by s.c. injection of $25 \mu \mathrm{g}$ PLP $_{139-151}$ (in $50 \mu \mathrm{l}$ PBS) into the right hind footpad. PBS alone was injected into the left footpad to serve as a control for measurements. As a negative control, we used mice sensitized with CFA alone. Footpad thickness was measured 12, 24, 48, and 72 hours after challenge by an experimenter blinded to sample identity using a caliper-type engineer's micrometer. The footpad swelling response was calculated as the thickness of the right footpad (receiving antigen) minus the baseline thickness of the left footpad (receiving PBS).

Proliferation assays and cytokine analysis. Spleen and lymph node cells were obtained from mice 15 days after PLP $_{139-151}$ sensitization, dissociated into single-cell suspension, and cultured for proliferation assays in flat-bottomed, 96-well microtiter plates (Falcon; BD) at a density of $5 \times 10^{5}$ viable cells per well in a total volume of $200 \mu 1$ RPMI-1640 medium (Invitrogen
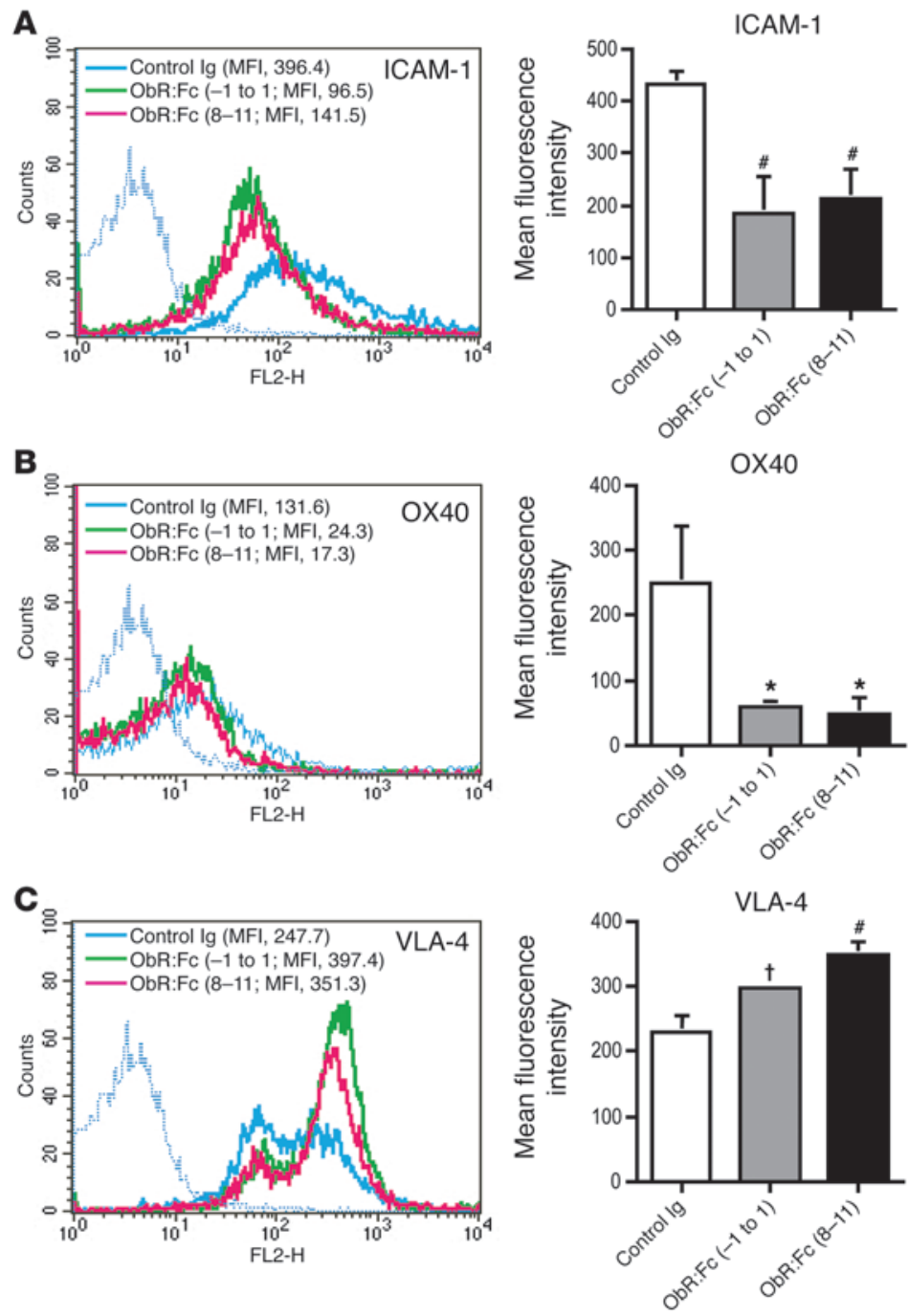
A

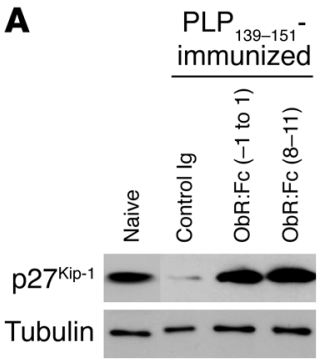

B

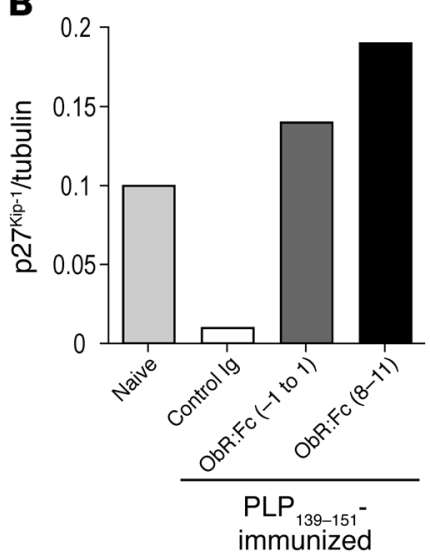

C

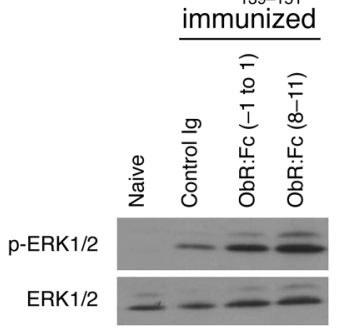

D

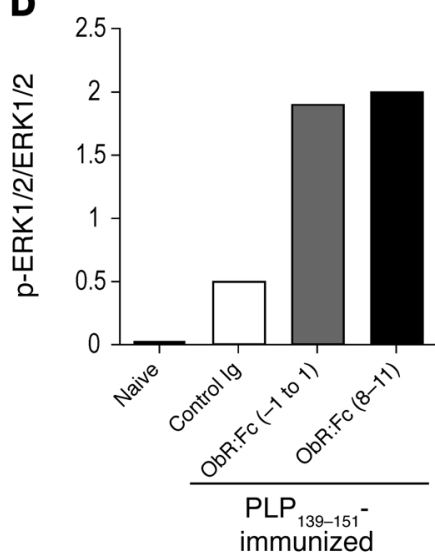

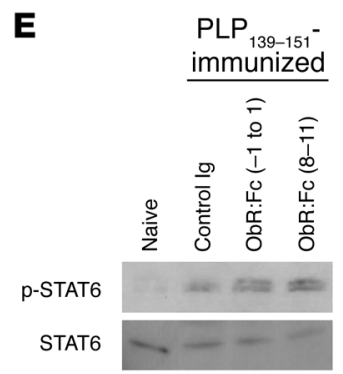

$\mathbf{F}$

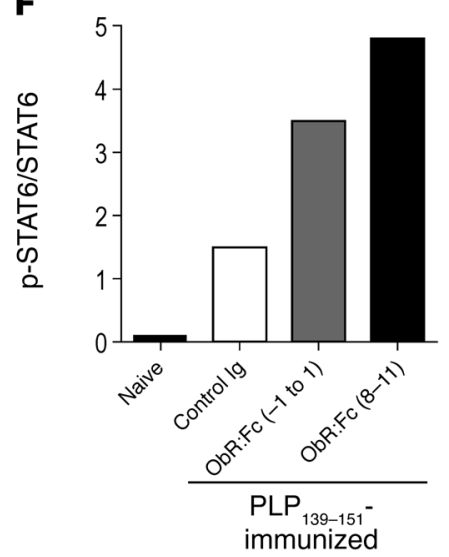

Figure 9

Leptin neutralization determines the failure to downmodulate the anergy factor p27 Kip-1 and is associated with sustained phosphorylation of ERK1/2 and STAT6. (A and B) Western blot analysis for p27Kip-1 and tubulin on purified CD4+ T cells obtained from SJL/J mice immunized with $\mathrm{PLP}_{139-151}$. Ex vivo analysis revealed high levels of p27 ${ }^{\mathrm{Kip}-1}$ in resting CD4+ $\mathrm{T}$ cells from naive mice; this phenomenon was accompanied by a strong downmodulation of p2 $7^{\text {Kip-1 }}$ in control Ig mice that developed classical EAE. Conversely, ObR:Fc treatment either from day -1 to day 1 or on days 8-11 caused a failure to downmodulate p2 $7^{\text {Kip-1 }}$, resulting in massive p27 Kip-1 accumulation. (C and D) Ex vivo analysis revealed very low levels of phosphorylation of ERK1/2 in resting CD4+ $T$ cells from naive mice. Conversely, control Ig-treated mice with EAE showed an increase in ERK1/2 phosphorylation. Leptin neutralization either from day -1 to day 1 or on days 8-11 induced sustained phosphorylation of the ERK1/2 molecule compared with control Ig-treated mice. (E and F) Ex vivo analysis revealed low levels of STAT6 phosphorylation in resting CD4+ $T$ cells from naive mice; conversely, control Ig-treated mice with EAE showed a modest increase in STAT6 phosphorylation. Leptin neutralization also induced marked phosphorylation of STAT6. For each panel, 1 representative experiment of 5 is shown.

Corp.) supplemented with $2 \%$ FCS (Invitrogen Corp.), 2 mM L-glutamine (Invitrogen Corp.), $0.1 \mathrm{mM}$ nonessential amino acids (Invitrogen Corp.), $1 \mathrm{mM}$ sodium pyruvate (Invitrogen Corp.), $50 \mu \mathrm{M} 2$-mercaptoethanol (Sigma-Aldrich), and $100 \mathrm{U} / \mathrm{ml}$ penicillin and $100 \mu \mathrm{g} / \mathrm{ml}$ streptomycin (Invitrogen Corp.). Cells were cultured at $37^{\circ} \mathrm{C}$ in $100 \%$ humidity and $5 \%$ $\mathrm{CO}_{2}$ in the presence or absence of varying concentrations of $\mathrm{PLP}_{139-151}$ peptide $(0-50 \mu \mathrm{g} / \mathrm{ml})$. As a control for proliferation, anti-CD3 Ab stimulation (2C11, $0.5 \mu \mathrm{g} / \mathrm{ml}$ final concentration; BD Biosciences - Pharmingen) was also performed. After $48-60$ hours' culture, cell supernatants (100 $\mu \mathrm{l})$ were removed from single wells and frozen at $-80^{\circ} \mathrm{C}$ for cytokine assay. IFN- $\gamma$, IL-4, and IL-10 were measured by ELISA developed in our laboratory using cytokine-specific capture and detection Abs (Abs R4-6A2 and XMG1.2 for detection of IFN- $\gamma$; Abs BVD4-1D11 and BVD6-24G2 for the detection of IL-4; and Abs JES5-2A5 and SXC-1 for the detection of IL-10) according to the manufacturer's instructions (BD Biosciences - Pharmingen). Standard curves for each assay were generated using recombinant mouse cytokines (IFN- $\gamma$, IL-4, and IL-10; BD Biosciences - Pharmingen), and the concentration of the cytokines in the cell supernatants was determined by extrapolation from the appropriate standard curve. The lower limits of detection for each assay were $2 \mathrm{pg} / \mathrm{ml}$ for IFN- $\gamma, 0.6 \mathrm{pg} / \mathrm{ml}$ for IL-4, and $3 \mathrm{pg} / \mathrm{ml}$ for IL- 10 . The remaining cells were incubated for an additional 16 hours, pulsed with $0.5 \mu \mathrm{Ci} /$ well of $\left[{ }^{3} \mathrm{H}\right]$ thymidine (Amersham Pharmacia Biotech), harvested on glass-fiber filters using a Tomtec (Orange) 96-well cell harvester, and counted in a 1205 Betaplate liquid scintillation counter (Wallac). Results obtained from triplicate cultures are expressed as mean $\mathrm{cpm} \pm \mathrm{SD}$.

Flow cytometry analysis. FITC-conjugated $\mathrm{mAbs}$ to CD11c, CD44, CD25, CD4, and Pan B (B220); PE-conjugated mAbs to CD14, CTLA-4 (CD152), CD40, VLA-4 (CD49d), ICAM-1 (CD54), OX-40, CD8, $\gamma \delta$, and NK; and allophycocyanin-conjugated $\mathrm{mAbs}$ to $\mathrm{CD} 45 \mathrm{RB}$ and $\mathrm{CD} 4$ were all purchased from BD Biosciences - Pharmingen. Isolated spleens and lymph nodes were prepared for flow cytometry by incubating cells with the appropriate Abs or control isotype-matched Abs followed by PBS washes. Data collection and analyses were performed on a FACScalibur flow cytometer (BD Biosciences - Immunocytometry Systems).

Western blot and biochemical analyses. Total cell lysates were obtained in $50 \mathrm{mM}$ HEPES (pH 7.5), $250 \mathrm{mM} \mathrm{NaCl}, 1$ mM EDTA, 1.0\% Triton X-100, $10 \mathrm{mM}$ sodium fluoride, $1 \mathrm{mM}$ sodium orthovanadate, and $2 \mu \mathrm{g} / \mathrm{ml}$ each of aprotinin, leupeptin, and pepstatin. Total proteins $(50 \mu \mathrm{g})$ from each lysate were subjected to SDS-PAGE under reducing conditions. After electrophoresis, proteins were transferred onto a nitrocellulose filter membrane (Protan; Schleicher \& Schuell BioScience) using a Trans-Blot Cell (Bio-Rad Laboratories) and transfer buffer containing $25 \mathrm{mM}$ Tris, $192 \mathrm{mM}$ glycine, and $20 \%$ methanol. Membranes were placed in $5 \%$ nonfat milk in PBS plus $0.5 \%$ Tween 20 (PBST) at $4{ }^{\circ} \mathrm{C}$ for 2 hours to block the nonspecific bind- 
ing sites. Filters were incubated with specific Abs before being washed 3 times in PBST and then incubated with a peroxidase-conjugated secondary $\mathrm{Ab}$ (Amersham Biosciences). After further washing with PBST, peroxidase activity was detected by using the ECL system (Amersham Biosciences). The Abs used were the following: anti-p2 $7^{\text {Kip-1 }}$, anti-STAT6, and antiphosphorylated STAT6 (Y641; all from Cell Signaling Technology Inc.); anti-ERK1/2 and anti-phosphorylated ERK1/2 (Santa Cruz Biotechnology Inc.); and anti-Foxp3 (eBioscience). The filters were also probed with an anti-tubulin $\mathrm{Ab}$ (Sigma-Aldrich) to normalize the amount of loaded protein. All filters were quantified by densitometric analysis of the bands utilizing the program ScionImage (version 1.63 for Mac; Scion Corp. Inc.)

Statistics. Analyses were performed using Mann-Whitney $U$ test (for unpaired 2-group analysis) and Kruskal-Wallis ANOVA test (for analysis of 3 or more groups). Results are expressed as mean $\pm \mathrm{SD}$; $P$ values less than 0.05 were considered statistically significant.

\section{Acknowledgments}

This work was supported by grants from Fondazione Italiana Sclerosi Multipla (FISM; 2001/R/68 and 2002/R/55), Regione Campania, and Fondo "Giacinta Magaldi" and by NIH grant AI063515 (to A. La Cava). The authors are particularly indebted to Salvatore Sequino for expert animal care, Armando Coppola for histological analysis, Antonio Di Giacomo for the protocol to obtain anti-leptin Abs, and Daniela Aufiero for ELISA assays. This work is dedicated to the memory of Eugenia Papa.

Received for publication August 8, 2005, and accepted in revised form November 11, 2005.

Address correspondence to: Giuseppe Matarese, Istituto di Endocrinologia e Oncologia Sperimentale, Consiglio Nazionale delle Ricerche (IEOS-CNR), c/o Dipartimento di Biologia e Patologia Cellulare e Molecolare, Università di Napoli "Federico II," via S. Pansini, 5-80131, Napoli, Italy. Phone: 39-081-7463311; Fax: 39-081-7463252; E-mail: gmatarese@napoli.com.

Veronica De Rosa and Claudio Procaccini contributed equally to this work.
1. Friedman, J.M., and Halaas, J.L. 1998. Leptin and the regulation of body weight in mammals. Nature. 395:763-770.

2. La Cava, A., and Matarese, G. 2004. The weight of leptin in immunity. Nat. Rev. Immunol. 4:371-379.

3. Fantuzzi, G., and Faggioni, R. 2000. Leptin in the regulation of immunity, inflammation, and hematopoiesis. J. Leukoc. Biol. 68:437-446.

4. Matarese, G., et al. 2001. Requirement for leptin in the induction and progression of autoimmune encephalomyelitis. J. Immunol. 166:5909-5916.

5. Sospedra, M., and Martin, R. 2005. Immunology of multiple sclerosis. Annu. Rev. Immunol. 23:683-747.

6. Zamvil, S.S., and Steinman, L. 1990. The T lymphocyte in experimental allergic encephalomyelitis. Annu. Rev. Immunol. 8:579-621.

7. Sanna, V., et al. 2003. Leptin surge precedes onset of autoimmune encephalomyelitis and correlates with development of pathogenic T cell responses. J. Clin. Invest. 111:241-250. doi:10.1172/JCI200316721.

8. Matarese, G., et al. 2005. Leptin increase in multiple sclerosis associates with reduced number of $\mathrm{CD} 4^{+} \mathrm{CD} 25^{+}$regulatory T cells. Proc. Natl. Acad. Sci. U.S. A. 102:5150-5155.

9. Lock, C., et al. 2002. Gene-microarray analysis of multiple sclerosis lesions yields new targets validated in autoimmune encephalomyelitis. Nat. Med. 8:500-508.

10. Denkinger, C.M., Denkinger, M., Kort, J.J., Metz, C., and Forsthuber, T.G. 2003. In vivo blockade of macrophage migration inhibitory factor ameliorates acute experimental autoimmune encephalomyelitis by impairing the homing of encephalitogenic $\mathrm{T}$ cells to the central nervous system. J. Immunol. 170:1274-1282.

11. Weinberg, A.D., Wengmann, K.W., Funatake, C., and Whintham, R.H. 1999. Blocking OX-40/OX-40 ligand interaction in vitro and in vivo leads to decreased $\mathrm{T}$ cell function and amelioration of experimental allergic encephalomyelitis. J. Immunol. 162:1818-1822.

12. Flugel, A., et al. 2001. Migratory activity and functional changes of green fluorescent effector cells before and during experimental autoimmune encephalomyelitis. Immunity. 14:547-560.

13. Theien, B.E., et al. 2001. Discordant effects of antiVLA-4 treatment before and after onset of relapsing experimental autoimmune encephalomyelitis. J. Clin. Invest. 107:995-1006.

14. Wells, A.D., Walsh, M.C., Bluestone, J.A., and Turka, L.A. 2001. Signaling through CD28 and CTLA-4 controls two distinct forms of T cell anergy. J. Clin. Invest. 108:895-904. doi:10.1172/JCI200113220.

15. Li, W., Whailey, C.D., Mendino, A., and Mueller, D.L. 1996. Blocked signal transduction to the ERK and JNK protein kinases in anergic $\mathrm{CD}^{+} \mathrm{T}$ cells. Science. 271:1272-1276.

16. Schwartz, R.H. 2003. T cell anergy. Annu. Rev. Immunol. 21:305-334.

17. Boussiotis, V.A., et al. 2000. p27kip1 functions as an anergy factor inhibiting interleukin-2 transcription and clonal expansion of alloreactive human and mouse helper T lymphocytes. Nat. Med. 6:290-297.

18. Chitnis, T., et al. 2001. Effect of targeted disruption of STAT4 and STAT6 on the induction of experimental autoimmune encephalomyelitis. J. Clin. Invest. 108:739-747. doi:10.1172/JCI200112563.

19. Lord, G.M., Matarese, G., Howard, J.K., Bloom, S.R., and Lechler, R.I. 2002. Leptin inhibits the anti-CD3-driven proliferation of peripheral blood $T$ cells but enhances the production of proinflammatory cytokines. J. Leukoc. Biol. 72:330-338.
20. Lord, G.M., et al. 1998. Leptin modulates the T-cell immune response and reverses starvation-induced immunosuppression. Nature. 394:897-901.

21. Bansal-Pakala, P., Jember, A.G., and Croft, M. 2001. Signaling through OX40 (CD134) breaks peripheral T-cell tolerance. Nat. Med. 7:907-912.

22. Stassen, M., et al. 2004. Human CD25+regulatory T cells: two subsets defined by the integrins alpha 4 beta 7 or alpha 4 beta 1 confer distinct suppressive properties upon $\mathrm{CD}^{+}{ }^{+} \mathrm{T}$ helper cells. Eur.J. Immunol. 34:1303-1311.

23. Kohm, A.P., Carpentier, P.A., Anger, H.A., and Miller, S.D. $2002 . \mathrm{CD}^{+} \mathrm{CD} 25^{+}$regulatory T cells suppress antigen-specific autoreactive immune responses and central nervous system inflammation during active experimental autoimmune encephalomyelitis. J. Immunol. 169:4712-4716.

24. Rowell, E.A., Walsh, M.C., and Well, A.D. 2005. Opposing roles for the cyclin-dependent kinase inhibitor p27kip 1 in the control of $\mathrm{CD}^{+} \mathrm{T}$ cell proliferation and effector function. J. Immunol. 174:3359-3368.

25. Chen, D., Heath, V., O'Garra, A., Johnston, J., and McMahon, M. 1999. Sustained activation of the Raf-MEK-ERK pathway elicits cytokine unresponsiveness in T cells. J. Immunol. 163:5796-5805.

26. von Eynatten, M., et al. 2005. Adipocytokines as a novel target for the anti-inflammatory effect of atorvastatin in patients with type 2 diabetes. Diabetes Care. 28:754-755.

27. Youssef, S., et al. 2002. The HMG-CoA reductase inhibitor, atorvastatin, promotes a Th2 bias and reverses paralysis in central nervous system autoimmune disease. Nature. 420:78-84.

28. Waiczies, S., et al. 2005. Atorvastatin induces T cell anergy via phosphorylation of ERK1. J. Immunol. 174:5630-5635. 